\title{
The Influence of Students' Personality Traits on their Perception of a Good Teacher within the Five-Factor Model of Personality
}

\author{
Anna Göncz, Lajos Göncz, Jasmina Pekić \\ Department of Psychology, Faculty of Philosophy, University of Novi Sad, Dr. \\ Zorana Djindjića 2, 21000 Novi Sad, Serbia \\ agenc@ff.uns.ac.rs, goncz@ff.uns.ac.rs, jpekic@ff.uns.ac.rs
}

\begin{abstract}
This paper investigates the extent to which it is possible to predict the influence of personality traits of students of computer sciences (i.e. natural and technical sciences, $n=$ 188) and of humanities (i.e. social and humanistic sciences, $n=250$ ) on their perception of a good teacher. The five-factor model of personality provided the theoretical framework of the research, in which personality traits are classified into five domains: neuroticism, extraversion, openness to experience, agreeableness and conscientiousness. Statistical analysis on the total sample $(n=443)$ at the domain level showed that about $20 \%$ of the criteria variance (assessment of personality characteristics ascribed to a good teacher using the Big Five Inventory questionnaire) was attributable to the predictors (selfassessment of personality dimensions using the same questionnaire). For the analysis of individual questionnaire items, the common variance was 15\%. Self-reports of openness, agreeableness and neuroticism were better predictors of evaluations of a good teacher than self-reports of extraversion and conscientiousness. The basic expectation of a good teacher was openness to experience, and the aspects of agreeableness and neuroticism that provide good interpersonal relations. Students of social and humanistic sciences favoured more extravert, open and conscientious teachers than natural and technical sciences students. The prediction of good teacher expectations (on the basis of personality characteristics) was more successful with the students of natural and technical sciences than with social and humanistic sciences students.
\end{abstract}

Keywords: personality traits of students; assessment of teachers; five-factor model of personality

\section{Introduction}

Research in which the personality of the teacher is considered in the context of a certain theory of personality represents a significant step forward. It provides a theoretical framework for the formulation of more specific hypotheses that are suitable for the empirical verification, and aids in the interpretation of findings. In 
addition, such an approach resolves certain methodological uncertainties regarding the manner of data collection. It makes replication of research easier, and allows generalizations of research findings. In this paper we report a study in which a variant of this approach was applied.

This paper sought to answer the following question: to what extent can students' assessments of personality (using the five-factor model) attributed to a good teacher be predicted based on the personality characteristics of the students? This paper also examined whether the prediction of a good teacher was more successful based on the personality characteristics of students from different disciplines, namely computer sciences and humanities. This represents a novel aspect of the current research.

\subsection{Methodological Dilemmas in Assessing the Personality of Teachers}

A review of the research related to the assessment of teachers' personality reveals that the issue of data collection has been resolved in various ways. Feldman [1] gave an overview of 72 studies: some researchers asked respondents to write a term paper on the characteristics of their most or least favoured teacher, while others opted for the technique of free guidance of characteristics or offered respondents a choice from a list of characteristics. The classification of responses and limited opportunities for in-depth statistical analysis of the data are weak points in most such studies. Although these procedures are still used [2], some progress has been made.

Lamke [3] was the first to introduce an approach that applied a questionnaire based on Cattell's theory of personality [4] for the (self) description of the characteristics and behaviour of successful and unsuccessful teachers. A similar approach was more recently employed by Mount, Barrick and Stewart [5] and Aidla and Vadi [6] using questionnaires based on the five-factor model of personality [7]. Rushton, Morgan and Richard [8] used a questionnaire based on Jung's theory [9, 10]), while Li and Wu [11] relied on Eysenck's [12] theory of personality. This approach is essentially a modified version of previous approaches in which respondents choose from a list of characteristics. However, a significant advantage of a technique that uses standardized questionnaires of personality is that the same list of descriptions is always offered. This facilitates the replication of studies and enables comparisons with results obtained from different samples. It can also enable generalization of the results.

As in Aidla and Vadi's study [6], the current study adopted the five-factor model of personality as the theoretical framework, using the Big Five Inventory (44-item version). 


\subsection{The Five-Factor Model of Personality as a Framework for Research on the Personality of the Teachers}

The five-factor model of personality describes the personality structure in terms of personality traits arranged along five dimensions, namely: neuroticism (N), extraversion (E), openness to experience (O), agreeableness (A) and conscientiousness $(\mathrm{C})$.

The dimension of neuroticism represents emotional lability or stability. Emotional lability is characterized by: the dominance of negative feelings; anxiety; depression and perturbation; difficulty in coping with stressful situations; poor impulse control; irrational reactions; and a tendency towards mental disorders, uncertainty and changeable moods. At the other end of the dimension are emotionally stable personalities who are rarely anxious, inoffensive, easily adapt to changes, not irritable or depressed, of balanced mood, calm, cold-blooded, and have good capacities for the prevalence of stress.

Extraversion is the dimension of sociability, and is, sometimes also considered a dimension of energy. The dominant characteristic of an extravert person is positive emotions. These individuals are confident, dynamic, active, talkative, excitement-seeking, ambitious, friendly, warm and enthusiastic. They have highly developed social skills and diverse interests. At the other extreme are introverts, who are aloof, calm, shy, thoughtful, and prefer to work independently. These individuals have developed an ability to concentrate and analyse, and they tolerate monotony well.

Openness to experience is described as receptivity to new experiences and culture, and is associated with a rich inner life, imaginativeness and creativity. Open people are willing to experiment. They are curious, tolerant and accept new values and ideas in a non-dogmatic manner. They are not slaves of the authorities, but neither are they inconsistent nor unprincipled. They have an expressed interest in art and science. At the other extreme of this dimension are closed people that are not inclined to change and innovation, and instead prefer the conventional and familiar. They are traditional, with conservative views, though they may not necessarily be authoritarian and intolerant.

Agreeableness represents another sociability dimension. Agreeable people are generous, sensitive to the needs of others, willing to help and forgive, mildmannered, modest, attentive, benevolent, and humane. Personal interests are not at the forefront. At the other end of the dimension are those disagreeable, distrustful, cynical, suspicious and insensitive, who do not consider the consequences of their actions.

Conscientiousness is the dimension of reliability, acceptance of responsibility, accuracy, durability, and adherence to policies and planning. Conscientious persons have developed work habits; they organize and systematically carry out their duties in a self-disciplined and deliberately planned manner. They are strong 
willed and are determined to achieve goals. If it is overly expressed, conscientiousness leads to compulsive neatness and pettiness. At the other end of the dimension are people who are more casual. Such individuals approach their duties in a disorganized manner and without an elaborate plan. They are less interested in achieving objectives and in this regard are less guided by ethical principles, though not necessarily immoral.

The most common application of the five-factor model is in the field of organizational behaviour, particularly in professional selection and occupation choice. Liao and Lee [13] found a significant positive effect of all dimensions on engagement in the workplace except for neuroticism, which had a negative effect. In addition, Barrick and Mount [14] found that conscientiousness was a good predictor of success in very different occupational groups, and extraversion may predict performance in occupations where social interaction is important. With regard to job satisfaction, a meta-analysis by Judge et al. [15] revealed a significant positive correlation with conscientiousness, extraversion and agreeableness, and a negative correlation with neuroticism, but only the relations with neuroticism and extraversion were found in all studies.

The dimensions of the five-factor model of personality can provide a basis on which to formulate certain expectations about preferred and undesirable personality characteristics of teachers. For instance, it seems reasonable to assume that the desirable traits of a good teacher would include low neuroticism, with pronounced extraversion, openness to experience, agreeableness (pleasantness) and (adaptive) conscientiousness. The extreme values in all domains are likely to be considered undesirable. Some of these assumptions are confirmed by empirical findings. Sanchez et al. [16] concluded that social science students at universities in Andalusia expected most of their teachers to have respect in their relations and be understanding (agreeableness), be open to cooperation without regard to personality characteristics (openness to experience), and have good teaching skills (conscientiousness). Aidla and Vadi [6] found that male teachers from Estonia were more agreeable and conscientious, but also less neurotic than the general population. The study of Genc et al. [17] confirmed that a good teacher is expected to have less emotional lability, with a prominence in extraversion, openness, agreeableness and conscientiousness.

Investigations of the determinants of students' assessment of a good teacher have focused primarily on gender. Studies have shown that expectations among females are more uniform [17]. Males are stricter, and females are milder in their evaluation of female teachers, while the assessment of male teachers does not depend on the assessor's gender [18]. 


\section{Method}

\subsection{Sample and Procedure}

Data were collected from 443 students at the University of Novi Sad, who were studying either natural and technical (or computer) sciences (Faculty of Science and Faculty of Engineering, subsample A, $n=188$ ) or social and human sciences (or humanities) (Faculty of Philosophy and Arts Academy, subsample $\mathrm{B}, n=250$ ). In subsample A, $60 \%$ of the respondents were female, with an average age of 21.85 years $(\mathrm{SD}=1.53$, range from 19 to 27 years). Their average mark in secondary school was 4.64 ( $\mathrm{SD}=1.53$ ) on a scale from one to five, and at the university they had, on a scale from five to ten, an average mark of 8.34 (SD = 0.57). In subgroup $\mathrm{B}, 77 \%$ were female and their mean age was 21.30 years ( $\mathrm{SD}=$ 0.72 , age range 21 to 25 years). The mean mark for achievement in secondary school was $4.80(\mathrm{SD}=0.46)$, and at university their average success was 8.46 (SD $=0.66$ ).

Students' self-assessment on the Big Five Inventory revealed that those studying natural and technical sciences were significantly more agreeable and conscientious than the students of social and humanistic sciences, while the students of humanistic orientation were marginally more open than the natural and technical sciences students.

All respondents provided information regarding their faculty and department, gender, age, and success both in high school and at the university. During completion of the questionnaire, for each statement students rated to what extent the statement related to themselves. They then put themselves in the position of the teachers and answered in terms of how they believed a good teacher would respond. Data were collected during classes and by using the "snowball" method. Participation in the survey was voluntary and was rewarded with additional points for the students' course. The respondents were informed about the research and the manner of protection of data anonymity. Ninety-eight $(20 \%)$ of respondents attended classes given in Hungarian and provided data in Hungarian.

\subsection{Instrument}

The current study employed the 44-item version of the Big Five Inventory (BFI) [19], using both the Serbian [20] and a Hungarian language version. The latter version was compiled with a back translation technique, and as a control, it utilized items both from the English version (available at http://www.outofservice.com/bigfive/) and a 132-item Hungarian version [21]. The questionnaire contains brief descriptions of personality, and the respondent rates the degree to which he/she agrees with every statement on a five-point scale (from $1=$ strongly disagree to $5=$ strongly agree). The items were selected on the basis of expert opinion regarding which were the best descriptors of the 
dimensions. Čolović [20] reported satisfactory indicators of convergent validity and different measures of the questionnaire reliability of the BFI (e.g. Cronbach's alpha coefficients of reliability of internal consistence for individual scales ranged from 0.72 to 0.80 for a Serbian population). In our study, Cronbach's alpha was 0.72 for neuroticism, 0.80 for extraversion, 0.88 for openness, 0.81 for agreeableness and 0.81 for conscientiousness. Given the small number of items in the subscales (eight for neuroticism and extraversion, nine for agreeableness and conscientiousness, and ten for openness) these are satisfactory indicators of reliability. The alpha coefficient for the entire scale was 0.88 , and the KaiserMeyer-Olkin (KMO) measure of sampling adequacy was 0.84 , which exceeded the recommended value of 0.60 .

To obtain a more complete picture, principal components analysis (PCA) was performed. Table 1 shows the correlations for students' self-assessment on the BFI. All correlations are significant, most of which have a low to moderate positive correlation, with the exception of the $\mathrm{N}$ scale which shows a low negative correlation. The scree_plot indicated that ten factors could be reasonably extracted from the items, i.e. that each dimension could be broken down into two subdimensions. This is consistent with earlier findings associated with the construction of various versions of the BFI [21, 22].

Table 1

Correlations between the BFI dimensions in our sample

\begin{tabular}{|l|llll|}
\hline Dimension & E & O & A & C \\
\hline $\mathrm{N}$ & $-0.241^{* *}$ & $-0.202^{* *}$ & $-0.241^{* *}$ & $-0.212^{* *}$ \\
$\mathrm{E}$ & & $0.285^{* *}$ & $0.271^{* *}$ & $0.252^{* *}$ \\
$\mathrm{O}$ & & & $0.175^{\text {** }}$ & $0.180^{\text {** }}$ \\
$\mathrm{A} / \mathrm{C}$ & & & & $0.403^{\text {** }}$ \\
\hline
\end{tabular}

Notes: $N=$ neuroticism $; E=$ extraversion; $O=$ openness to experience; $A=$ agreeableness $; C=$ conscientiousness. $* *=p<0.01$

The instrument is brief and easily applicable, but does not provide sufficient nuanced description of personality.

\subsection{Hypotheses}

It was assumed that the appraisers' personality characteristics would be an important determinant of rated characteristics of a (good) teacher. Therefore, this study tested the following hypotheses. (1) We expected a significant positive correlation between self-assessed personality characteristics and assessed characteristics of a good teacher for dimensions (more robust traits of higher order). (2) A significant positive correlation was also predicted at the level of individual items (specific features of lower order) by which the dimensions are defined. (3) It was also assumed that in both groups of students the variance in ratings of a good teacher would be explained by personality characteristics to the same extent, i.e. self-reports of personality traits have the same predictive power with respect to their expectations of a good teacher. 


\subsection{Data Processing}

Data were analysed using statistical packages SPSS (version 19) and Statistics (version 10). In addition to descriptive indicators, $t$-tests and analysis of variance were used for group comparisons. To examine the relationships between correlation coefficients, canonical correlation and regression analysis techniques were conducted.

\section{Results and Discussion}

\subsection{Descriptive Indicators and Correlations Among Variables}

Table 2 shows the descriptive statistics for predictor variables (self-evaluation of BFI dimensions) and the criterion variables (evaluation of a good teacher using BFI dimensions) for the total sample and subsamples. Table 3 shows the correlations between these variables.

Table 2

Descriptive statistics for predictor and criterion variables

\begin{tabular}{|l|lllllll|}
\hline Variables & $\mathrm{N}$ & Min & Max & M & SD & Sk & $\mathrm{Ku}$ \\
\hline $\begin{array}{l}\text { Predictor } \\
\text { BFI self-assessment: total sample }\end{array}$ & & & & & \\
Dimensions & & & & & & & \\
$\mathrm{N}$ & 420 & 9 & 38 & 22.79 & 5.13 & 0.04 & 0.00 \\
$\mathrm{E}$ & 433 & 9 & 40 & 29.62 & 5.77 & -0.47 & -0.02 \\
$\mathrm{O}$ & 428 & 12 & 50 & 38.70 & 6.92 & -0.78 & 0.87 \\
$\mathrm{~A}$ & 432 & 17 & 45 & 35.97 & 5.32 & -0.50 & -0.20 \\
$\mathrm{C}$ & 432 & 13 & 45 & 31.56 & 5.78 & -0.22 & -0.01 \\
BFI self-assessment: subsamples & & & & & \\
Subsample A* & & & & & & & \\
Dimensions & & & & & & & \\
N & 171 & 9 & 37 & 22.56 & 5.65 & 0.20 & -0.27 \\
E & 174 & 12 & 40 & 29.59 & 5.63 & -0.36 & -0.39 \\
O & 173 & 16 & 50 & 37.92 & 7.12 & -0.74 & 0.19 \\
C & 173 & 17 & 45 & 36.56 & 5.39 & -0.71 & 0.37 \\
A & 173 & 19 & 45 & 31.71 & 5.65 & 0.03 & -0.70 \\
Subsample B** & & & & & & & \\
Dimensions & & & & & & & \\
N & 244 & 9 & 38 & 22.99 & 4.78 & -0.10 & 0.27 \\
E & 243 & 12 & 40 & 29.74 & 5.86 & -0.44 & -0.18 \\
O & 240 & 12 & 50 & 39.41 & 6.54 & -0.86 & 1.52 \\
A & 243 & 20 & 45 & 35.56 & 5.21 & -0.30 & -0.58 \\
C & 243 & 13 & 45 & 31.53 & 5.87 & -0.40 & 0.31 \\
Criterion & & & & & & & \\
BFI ratings of good teacher: total sample & & & & & \\
\hline
\end{tabular}




\begin{tabular}{|c|c|c|c|c|c|c|c|}
\hline \multicolumn{8}{|c|}{ Dimensions } \\
\hline $\mathrm{N}$ & 430 & 8 & 38 & 19.43 & 4.54 & -0.10 & 0.12 \\
\hline $\mathrm{E}$ & 428 & 16 & 40 & 32.72 & 3.76 & -0.63 & 0.97 \\
\hline $\mathrm{O}$ & 426 & 17 & 50 & 42.35 & 5.48 & -0.99 & 0.97 \\
\hline $\mathrm{C}$ & 427 & 15 & 45 & 38.77 & 4.32 & -0.76 & 0.43 \\
\hline A & 429 & 18 & 45 & 38.07 & 4.66 & -0.82 & 0.86 \\
\hline \multicolumn{8}{|c|}{ BFI ratings of good teacher: subsamples } \\
\hline \multicolumn{8}{|c|}{ Subsample A* } \\
\hline \multicolumn{8}{|c|}{ Dimensions } \\
\hline $\mathrm{N}$ & 171 & 10 & 38 & 19.23 & 4.84 & 0.28 & 0.22 \\
\hline $\mathrm{E}$ & 172 & 16 & 40 & 31.80 & 3.83 & -0.60 & 0.83 \\
\hline $\mathrm{O}$ & 171 & 17 & 50 & 40.47 & 6.25 & -0.98 & 0.19 \\
\hline A & 172 & 15 & 45 & 38.20 & 4.69 & -1.15 & 2.58 \\
\hline $\mathrm{C}$ & 171 & 18 & 45 & 36.36 & 5.21 & --0.61 & 0.20 \\
\hline \multicolumn{8}{|c|}{ Subsample B** } \\
\hline \multicolumn{8}{|c|}{ Dimensions } \\
\hline $\mathrm{N}$ & 244 & 8 & 30 & 19.60 & 4.28 & -0.43 & 0.09 \\
\hline $\mathrm{E}$ & 240 & 16 & 40 & 33.23 & 3.59 & -0.66 & 1.26 \\
\hline $\mathrm{O}$ & 240 & 28 & 50 & 43.64 & 4.49 & -0.86 & 0.65 \\
\hline A & 241 & 19 & 45 & 39.10 & 4.04 & -1.16 & 2.86 \\
\hline $\mathrm{C}$ & 242 & 23 & 45 & 39.13 & 3.88 & -0.64 & 0.72 \\
\hline
\end{tabular}

Notes: $N=$ number of respondents; Min = minimal row score; Max = maximal row score; $M=$ mean; $S D=$ standard deviation; $S k=$ skewness; Ku $=-$ Kurtosis; $N=$ neuroticism; $E=$ extraversion; $O=$ openness to experience; $A=$ agreeableness; $C=$ conscientiousness. $*$ indicates students of computer sciences; ** indicates students of humanities

The indicators in Table 2 show that the skewness and kurtosis scores for the total sample are very good (less than 1), and are generally acceptable for the subsamples. The subsample comparisons for BFI self-assessment showed that the students of natural and technical sciences were significantly more agreeable ( $\mathrm{p}<$ $0.05)$ and more conscientious $(\mathrm{p}<0.10)$ than the students of social and humanistic sciences, whereas the latter students were marginally more open $(\mathrm{p}<0.10)$ than the students of natural and technical sciences.

Table 3

Correlations between self-assessed BFI dimensions and general characteristics of the student sample with the students' BFI evaluations of a good teacher (Pearson r): total sample

\begin{tabular}{|c|c|c|c|c|c|}
\hline \multirow[t]{2}{*}{ Student variables } & \multicolumn{5}{|c|}{ Good teacher evaluation } \\
\hline & $\mathrm{N}$ & $\mathrm{E}$ & $\mathrm{O}$ & A & $\mathrm{C}$ \\
\hline \multicolumn{6}{|l|}{ Self-assessment } \\
\hline $\mathrm{N}$ & $\underline{0.441 * *}$ & $-0.160 * *$ & -0.074 & $-0.156 * *$ & $-0.128 * *$ \\
\hline $\mathrm{E}$ & & $-0.370 * *$ & $0.118 *$ & $0.203^{* *}$ & $0.197 * *$ \\
\hline $\mathrm{O}$ & & & $\underline{0.495 * *}$ & $0.249 * *$ & $0.295 * *$ \\
\hline A & & & & $0 . \underline{484 * *}$ & $0.217 * *$ \\
\hline $\mathrm{C}$ & & & & & $\underline{0.313 * *}$ \\
\hline \multicolumn{6}{|l|}{ Sample characteristics } \\
\hline Gender & -0.054 & $0.118 *$ & 0.092 & $0.118 *$ & 0.074 \\
\hline Faculty & 0.054 & $0.174 *$ & $0.271 * *$ & $0.098^{*}$ & $0.291 * *$ \\
\hline 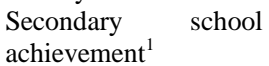 & -0.077 & $0.196 * *$ & $0.141 * *$ & $0.134 * *$ & $0.156^{* *}$ \\
\hline $\begin{array}{l}\text { University } \\
\text { achievement }\end{array}$ & -0.037 & $0.111 *$ & $0.116^{*}$ & 0.063 & $0.100^{*}$ \\
\hline
\end{tabular}




\begin{tabular}{|c|c|c|c|c|c|}
\hline $\begin{array}{l}\text { Testing language (S or } \\
\mathrm{H})\end{array}$ & $-0.353 * *$ & $0.124 *$ & 0.002 & $0.162 * *$ & -0.37 \\
\hline Age (years) & 0.016 & -0.065 & $0.248 * *$ & 0.068 & $-0.312 * *$ \\
\hline
\end{tabular}

The data shown in the upper part of Table 3 refer to the validation of the first hypothesis and are commented on in the next section. Here we are just noting that the results support the hypothesis, which suggests that the students' personality characteristics played a significant role in their evaluation of a good teacher (in terms of the five-factor model dimensions). The lower part of Table 3 shows a low but significant correlation between the sample characteristics and evaluations of a good teacher. The implications of these relations were analyzed in Table 6.

\subsection{Validation of the First Hypothesis: the Relationship Between Self-Assessment and the Evaluation of a Good Teacher (in Terms of BFI Dimensions) for the Total Sample}

The first hypothesis assumed a significant positive correlation (at the level of BFI dimensions) between self-assessment and the evaluation of a good teacher.

The upper part of Table 3 shows that students' self-assessment and their evaluation of a good teacher for the same dimensions of the BFI have a positive correlation of medium intensity (underlined in the table), according to the recommendations by Cohen [23] regarding interpretation of the strength of the relationship between the variables. Openness to experience $(r=0.495)$ showed the most pronounced covariation, followed by agreeableness $(r=0.484)$, neuroticism $(r=441)$, extraversion $(r=0.370)$ and conscientiousness $(r=0.313)$. Preliminary analysis confirmed that the assumptions of normality, linearity and homogeneity of variance were satisfied; hence, it can be concluded that, for openness to experience, $24.5 \%$ of the variance of one variable was determined by the variance of the other. The coefficient of determination was $23.4 \%$ for agreeableness, $19.4 \%$ for neuroticism, $13.7 \%$ for extraversion and $9.8 \%$ for conscientiousness. These results suggest that self-assessment of openness to experience had the greatest influence on the students' evaluation of a good teacher, followed by agreeableness. For the questionnaire as a whole, the correlation was of medium intensity $\left(r=0.443\right.$, and the coefficient of determination $r^{2}=0,196$ suggested about $20 \%$ of the common variance), which supports our first hypothesis.

Table 3 also shows low but significant correlations between most self-assessments on a specific BFI dimension with assessments of a good teacher for the other dimensions. However, the correlation between the self-assessments of neuroticism and evaluations of teacher openness was not significant. Overall, this indicates that self-assessments of personality dimensions are to some extent a predictor of evaluations of a good teacher on some other dimension. 
Canonical correlation analysis (and standard and hierarchical multiple regression analyses) was conducted to enable a more detailed interpretation (Tables 4-6). The analysis showed a significant association between predictor (BFI selfassessments) and criterion variables (evaluations of a good teacher) ( $\mathrm{r}=53, \mathrm{p}<$ 0.001 ), which explained $28.53 \%$ of the common variance (about $9 \%$ higher than when the common variance was determined by coefficients of determination using a bivariate correlation, probably due to shared disruptive variables). As many as five pairs of significant canonical factors were extracted, of which from the first three specific relevant conclusions for our research could be deduced. Table 4 shows the matrix structure for these pairs of canonical factors.

Table 4

The factor structure of the three canonical factors for the correlations between predictor and criterion variables

\begin{tabular}{|l|lll|}
\hline BFI dimensions & $\begin{array}{l}\text { Student personality (predictor } \\
\text { variables): correlations with } \\
\text { canonical factor }\end{array}$ & $\begin{array}{l}\text { Good teacher } \\
\text { (criterion } \\
\text { correlations } \\
\text { factor }\end{array}$ & $\begin{array}{l}\text { personality } \\
\text { variables): } \\
\text { canonical }\end{array}$ \\
\hline First factor & & & \\
N & 0.456 & 0.628 & \\
E & 0.407 & 0.198 & \\
O & -0.659 & -0.927 & \\
A & 0.649 & 0.863 & \\
C & 0.043 & 0.103 & \\
Second factor & -0.486 & 0.593 & \\
N & 0.209 & 0.198 & \\
E & -0.310 & 0.038 & \\
O & -0.631 & -0.691 & \\
A & -0.141 & -0.059 & \\
C & & & \\
Third factor & -0.757 & -0.704 & \\
N & -0.244 & -0.080 & \\
E & -0.743 & -0.777 & \\
O & -0.121 & -0.172 & \\
A & -0.049 & -0.132 & \\
C & E & & \\
\hline
\end{tabular}

Notes: $\mathrm{N}=$ neuroticism; $\mathrm{E}=$ extraversion; $\mathrm{O}=$ openness to experience; $\mathrm{A}=$ agreeableness; $\mathrm{C}=$ conscientiousness

Correlations with the first canonical factor suggest that the evaluations of a good teacher were primarily determined by the students' self-assessments on dimensions of openness to experience, agreeableness and neuroticism, and less so by extraversion. Conscientiousness had no significant impact on this factor. Very similar relationships were obtained for the linear correlation. However, the structure of relationships affected by the first factor further indicates that conservative students (negative correlation for openness to experience) expected a good teacher to be more conservative, but also more agreeable and more emotionally stable, and somewhat less extraverted. The second pair of canonical 
factors revealed that self-assessed agreeableness, and even neuroticism, were better determinants of the characteristics of a good teacher than openness to experience, and the weakly expressed role of extraversion remained slightly more prominent than conscientiousness. The third pair of factors provided more information about the role of neuroticism and openness to experience as predictors of good teacher evaluations. Emotionally stable students also expected emotional stability from a good teacher, and those who were open to experience had the same evaluations of a good teacher. Overall, this analysis revealed that selfassessments on the dimensions of openness to experience, agreeableness and neuroticism were better predictors of perceptions of a good teacher than selfassessments in the domain of extraversion and conscientiousness. In addition, students' self-assessments and evaluations of teachers for these dimensions were similar in terms of direction and were of greater intensity. If, for example, the evaluator was ranked highly on emotional stability or agreeableness, he/she expected even more pronounced emotional stability and agreeableness from a good teacher. For openness to experience the relationship was more complex: it seems that an open estimator wants an open teacher as well, but more pronounced conservatism (i.e. low openness) in students was related with their expectation to even greater conservatism in teachers.

Table 5

Standard multiple regression analysis: estimation of the model in terms of the prediction of personality traits of a good teacher and the partial contributions of predictors

\begin{tabular}{|c|c|c|c|c|c|c|}
\hline $\mathrm{M}$ & $\mathrm{r}$ & $\mathrm{r}^{2}$ & $\begin{array}{l}\text { Corrected } \\
\mathrm{r}^{2}\end{array}$ & $\begin{array}{l}\text { Standard } \\
\text { error } \\
\text { of estimate }\end{array}$ & $\mathrm{F}$ & $\mathrm{p}$ \\
\hline 1 & $0.456^{\mathrm{a}}$ & 0.208 & 0.198 & 11.962 & 21.118 & 0.0001 \\
\hline Predictors & & & & Beta & $\mathrm{t}$ & $\mathrm{p}$ \\
\hline $\mathrm{N}$ & & & & 0.139 & 2.944 & 0.003 \\
\hline $\mathrm{E}$ & & & & 0.134 & 2.771 & 0.006 \\
\hline $\mathrm{O}$ & & & & 0.304 & 6.468 & 0.000 \\
\hline A & & & & 0.163 & 3.258 & 0.001 \\
\hline $\mathrm{C}$ & & & & 0.102 & 2.055 & 0.040 \\
\hline
\end{tabular}

Notes: $M=$ model. Predictors: self-assessment of neuroticism $(N)$, extraversion $(E)$, openness $(O)$, agreeableness (A) and conscientiousness $(C)$. Dependent variable: BFI assessments of a good teacher

Table 5 shows the results of the standard multiple regression analysis. The regression model, in which evaluations of a good teacher (in terms of the BFI dimensions) were the criterion variables and the raw scores for BFI selfassessment were regarded as the predictor variables, was statistically significant ( $\mathrm{F}$ $(5,403)=21.118, \mathrm{p}=0.0001)$. The predictor variables explained $19.8 \%$ of the criteria, which is almost identical to the common variance obtained by calculating the bivariate correlations. Both the regression model and bivariate correlation indicated that each predictor significantly contributed to the prediction, but with different intensity. Openness to experience had the largest contribution (beta $=$ $0.304, p=0.000)$. This was followed by agreeableness (beta $=0.163 \mathrm{p}=0.001$ ), 
neuroticism (beta $=0.139, \mathrm{p}=0.003$ ) extraversion (beta $=0.134, \mathrm{p}=0.006$ ) and conscientiousness (beta $=0.102, p=0.040$ ). Pearson's $r$ indicated the same order. However, regression analysis using this more restrictive regression model (which removes part of the common variance attributable to overlapping between predictor variables), showed that the intensity of those relationships was far weaker than on the basis of linear correlation. The coefficients of determination in the linear correlations ranged from $9.8 \%-24.5 \%$, but for this regression analysis the range was from $1 \%$ (for conscientiousness) to $9.2 \%$ (for openness to experience).

This analysis confirmed that the self-assessment scores for the BFI dimensions as a group or block explain about $20 \%$ of the variance of the dependent variable, and that each individual dimension significantly contributes to explaining the unique variance of the dependent variable. Additional information obtained from this analysis that is of theoretical importance includes the fact that the individual contributions of each domain, if overlapping within them is excluded, are of significantly lower intensity. With such analysis, openness to experience explains about $9 \%$ of the variability in the assessment of a good teacher.

Relations between students' self-assessment and their evaluation of a good teacher on the BFI dimensions were also tested by hierarchical (sequential) multiple regression analysis with the disruptive effects of sample characteristics and testing language removed (the effects of such factors can be seen in the lower part of Table 3). This analysis sought to examine whether BFI self-assessments of the dimensions could still predict a significant part of the variance in the evaluation of a good teacher when the possible influence of such factors were removed. The main results of this analysis, which have more theoretical than practical importance for the current research, are presented in Table 6.

Table 6

Hierarchical multiple regression analysis: estimation of the model in terms of the prediction of BFI personality traits of a good teacher and the partial contributions of predictors

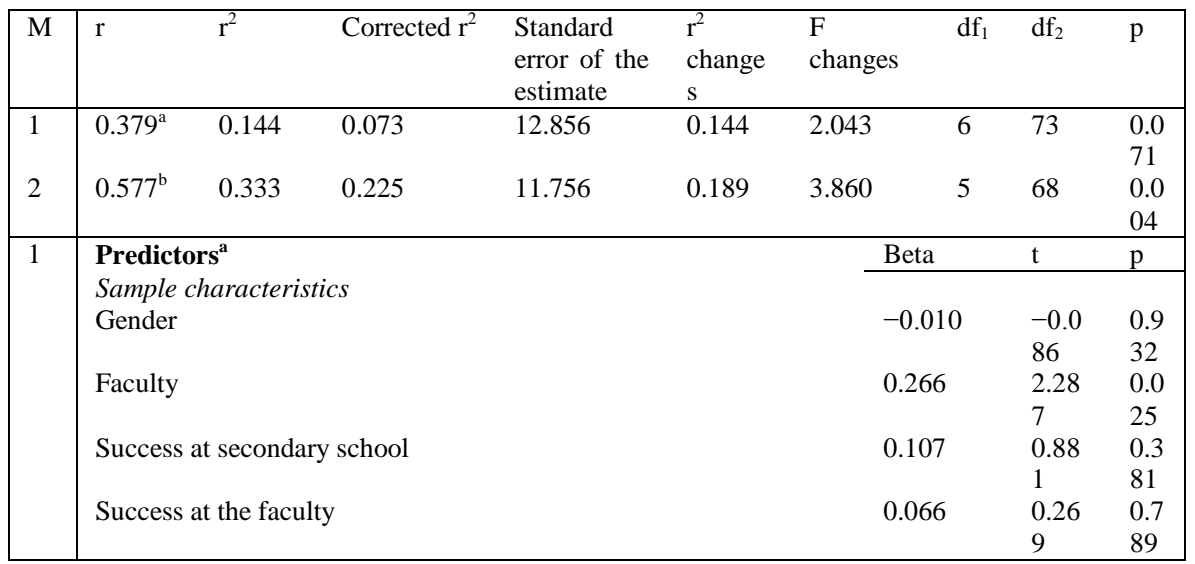




\begin{tabular}{|c|c|c|c|c|}
\hline & Testing language/ ethnic affiliation & 0.040 & 0.35 & 0.7 \\
\hline & & & 1 & 27 \\
\hline & Age/year of study & -0.166 & -1.4 & 0.1 \\
\hline & & & 61 & 48 \\
\hline 2 & Predictors $^{\mathrm{b}}$ & & & \\
\hline & Sample characteristics & & & \\
\hline & Gender & -0.086 & -0.7 & 0.4 \\
\hline & & & 87 & 34 \\
\hline & Faculty & 0.276 & 2.54 & 0.0 \\
\hline & & & 8 & 13 \\
\hline & Success at secondary school & 0.063 & 0.56 & 0.5 \\
\hline & & & 2 & 76 \\
\hline & Success at the faculty & 0.031 & 0.26 & 0.7 \\
\hline & & & 9 & 89 \\
\hline & Testing language/ethnic affiliation & 0.056 & 0.53 & 0.5 \\
\hline & & & 7 & 93 \\
\hline & Age/year of study & -0.179 & -1.6 & 0.1 \\
\hline & & & 58 & 02 \\
\hline & BFI self-assessment dimensions & & & \\
\hline & $\mathrm{N}$ & 0.171 & 1.55 & 0.1 \\
\hline & & & 4 & 25 \\
\hline & $\mathrm{E}$ & 0.151 & 1.37 & 0.1 \\
\hline & & & 4 & 74 \\
\hline & $\mathrm{O}$ & 0.262 & 2.47 & 0.0 \\
\hline & & & 2 & 16 \\
\hline & A & 0.195 & 1.71 & 0.0 \\
\hline & & & 2 & 92 \\
\hline & $\mathrm{C}$ & 0.095 & 0.82 & 0.4 \\
\hline & & & 7 & 11 \\
\hline
\end{tabular}

Notes: $M=$ model. ${ }^{a}$ Predictors: gender, faculty, success at secondary school, success at the faculty, testing languagelethnic affiliation, age/years of study (characteristics of the sample). ${ }^{b}$ Predictors: gender, faculty, success at secondary school, success at the faculty, testing languagelethnic affiliation, age/years of study, and self-assessment of neuroticism $(N)$, extraversion $(E)$, openness $(O)$, agreeableness $(A)$ and conscientiousness $(C)$. Dependent variable: BFI - good teacher

The sample characteristics entered in the first step explained $14.4 \%$ of the variance of evaluations of a good teacher (previous analyses showed that the requirements of normality, linearity, multicollinearity and homogeneity of variance were met). The model was marginally significant, and only the faculty affiliation had a notable beta coefficient. This suggests that predictions of good teacher assessments were somewhat more successful for the students of natural and technical sciences than for the students' of social and humanistic sciences. In the second block the self-assessment scores in the BFI domains were entered, and the model as a whole explained $33.3 \%$ of the total variance of the dependent variable. After removing the influence of sample characteristics, the selfassessments of students explained an additional $18.9 \%$ of the variance in the assessment of a good teacher. In the final model, only two indicators were important: the student's faculty and self-assessments of openness to experience. There was also a slight tendency for the dimension of agreeableness. The common variance was only slightly different (less than 1\%) from that indicated by the standard multiple regression. However, the partial contributions of selfassessments as the predictors of criterion variables were far less pronounced than indicated by the bivariate correlation and standard regression analysis. Only 
openness to experience had an effect of moderate intensity (about 7\%, compared with $9 \%$ in the standard regression analysis), and for the other predictors ranged from 0.9 to $3.8 \%$. With the exception of openness to experience, the prominence of the predictors varied.

\subsection{Validation of the Second Hypothesis: the Relationship Between Self-Assessment and the Evaluation of a Good Teacher for Individual Questionnaire Items (Total Sample)}

In the second hypothesis, we assumed that the students' self-assessments and their assessments of a good teacher would be significantly positively correlated in terms of individual BFI questionnaire items, which would also suggest that their perceptions of a good teacher were significantly determined by personality characteristics. As shown in Table 7, the average correlation was of moderate intensity $(r=0.387)$, and the coefficient of determination $\left(r^{2}=14.98\right)$ indicated that the common variance was about $15 \%$. As the dimensions contain 8-10 items, it was expected that the prediction of the properties of a good teacher based on individual items would on average be poorer than prediction based on the dimensions when the common variance is $19.8 \%$.

Table 7

Correlation matrix of individual BFI questionnaire items ${ }^{*}$ between students' self-assessment and their evaluation of a good teacher (Pearson's r)

\begin{tabular}{|c|c|c|c|c|c|c|c|c|c|c|c|}
\hline \multicolumn{12}{|c|}{ Average correlation: $r=0.387(\mathrm{SD}=0.099), \mathrm{r}^{2}=14.98$} \\
\hline I & $\begin{array}{l}\mathrm{M}_{1} \\
\mathrm{M}_{2}\end{array}$ & $\mathrm{r}$ & I & $\begin{array}{l}\mathrm{M}_{1} \\
\mathrm{M}_{2}\end{array}$ & $\mathrm{r}$ & I & $\begin{array}{l}\mathrm{M}_{1} \\
\mathrm{M}_{2}\end{array}$ & $\mathrm{r}$ & I & $\begin{array}{l}M_{1} \\
M_{2}\end{array}$ & $\mathrm{r}$ \\
\hline 1 & $\begin{array}{l}3.80 \\
4.12\end{array}$ & $\begin{array}{l}0.253 * \\
*\end{array}$ & 12 & $\begin{array}{l}4.05 \\
4.29\end{array}$ & $\begin{array}{l}0.317 * \\
*\end{array}$ & 23 & $\begin{array}{l}2.43 \\
3.50\end{array}$ & $\begin{array}{l}0.350 * \\
*\end{array}$ & 34 & $\begin{array}{l}2.91 \\
2.98\end{array}$ & $\begin{array}{l}0.454 * \\
*\end{array}$ \\
\hline 2 & $\begin{array}{l}3.37 \\
3.90\end{array}$ & $\begin{array}{l}0.364 * \\
*\end{array}$ & 13 & $\begin{array}{l}4.32 \\
4.63\end{array}$ & $\begin{array}{l}0.406^{*} \\
*\end{array}$ & 24 & $\begin{array}{l}2.61 \\
1.94\end{array}$ & $\begin{array}{l}0.390 * \\
*\end{array}$ & 35 & $\begin{array}{l}3.17 \\
3.33\end{array}$ & $\begin{array}{l}0.536 * \\
*\end{array}$ \\
\hline 3 & $\begin{array}{l}3.99 \\
4.66\end{array}$ & $\begin{array}{l}0.345^{*} \\
*\end{array}$ & & $\begin{array}{l}3.55 \\
2.91\end{array}$ & $\begin{array}{l}0.510 * \\
*\end{array}$ & 25 & $\begin{array}{l}4.00 \\
4.52\end{array}$ & $\begin{array}{l}0.260 * \\
*\end{array}$ & 36 & $\begin{array}{l}4.30 \\
4.47\end{array}$ & $\begin{array}{l}0.370 \\
*\end{array}$ \\
\hline 4 & $\begin{array}{l}1.69 \\
1.60\end{array}$ & $\begin{array}{l}0.334 * \\
*\end{array}$ & 15 & $\begin{array}{l}3.92 \\
4.36\end{array}$ & $\begin{array}{l}0.413 * \\
*\end{array}$ & 26 & $\begin{array}{l}4.02 \\
4.46\end{array}$ & $\begin{array}{l}0.329 * \\
*\end{array}$ & 37 & 3.32 & $\begin{array}{l}0.387^{*} \\
*\end{array}$ \\
\hline 5 & $\begin{array}{l}3.84 \\
4.44\end{array}$ & $\begin{array}{l}0.319 * \\
*\end{array}$ & 16 & $\begin{array}{l}3.99 \\
4.53\end{array}$ & $\begin{array}{l}0.390 * \\
*\end{array}$ & 27 & $\begin{array}{l}4.14 \\
4.31\end{array}$ & $\begin{array}{l}0.447 * \\
*\end{array}$ & 38 & $\begin{array}{l}3.62 \\
4.39\end{array}$ & $\begin{array}{l}0.312 \\
*\end{array}$ \\
\hline 6 & $\begin{array}{l}3.20 \\
3.21\end{array}$ & $\begin{array}{l}0.339 * \\
*\end{array}$ & 17 & $\begin{array}{l}4.23 \\
4.44\end{array}$ & $\begin{array}{l}0.436 * \\
*\end{array}$ & 28 & $\begin{array}{l}3.91 \\
4.47\end{array}$ & $\begin{array}{l}0.511 * \\
*\end{array}$ & 39 & $\begin{array}{l}2.98 \\
2.02\end{array}$ & $\begin{array}{l}0.387^{*} \\
*\end{array}$ \\
\hline 7 & $\begin{array}{l}4.24 \\
4.54\end{array}$ & $\begin{array}{l}0.385 * \\
*\end{array}$ & 18 & $\begin{array}{l}3.53 \\
4.28\end{array}$ & $\begin{array}{l}0.275 * \\
*\end{array}$ & 29 & $\begin{array}{l}3.01 \\
3.01\end{array}$ & $\begin{array}{l}0.832 * \\
*\end{array}$ & 40 & $\begin{array}{l}4.21 \\
4.45\end{array}$ & $\begin{array}{l}0.385^{*} \\
*\end{array}$ \\
\hline 8 & $\begin{array}{l}2.55 \\
3.44\end{array}$ & $\begin{array}{l}0.317 * \\
*\end{array}$ & 19 & $\begin{array}{l}3.34 \\
3.06\end{array}$ & $\begin{array}{l}0.296 * \\
*\end{array}$ & 30 & $\begin{array}{l}4.19 \\
4.34\end{array}$ & $\begin{array}{l}0.493 * \\
*\end{array}$ & 41 & $\begin{array}{l}3.79 \\
4.13\end{array}$ & $\begin{array}{l}0.381 * \\
*\end{array}$ \\
\hline 9 & $\begin{array}{l}2.66 \\
1.88\end{array}$ & $\begin{array}{l}0.338 * \\
*\end{array}$ & 20 & $\begin{array}{l}4.07 \\
4.43\end{array}$ & $\begin{array}{l}0.283 * \\
*\end{array}$ & 31 & $\begin{array}{l}2.95 \\
3.69\end{array}$ & $0.400 *$ & 42 & $\begin{array}{l}4.18 \\
4.59\end{array}$ & $\begin{array}{l}0.382 \\
*\end{array}$ \\
\hline 10 & $\begin{array}{l}4.25 \\
4.47\end{array}$ & $\begin{array}{l}0.462 * \\
*\end{array}$ & 21 & $\begin{array}{l}3.44 \\
3.77\end{array}$ & $\begin{array}{l}0.292 * \\
*\end{array}$ & 32 & $\begin{array}{l}4.05 \\
4.38\end{array}$ & $\begin{array}{l}0.372 * \\
*\end{array}$ & 43 & $\begin{array}{l}3.11 \\
4.03\end{array}$ & $\begin{array}{l}0.295^{*} \\
*\end{array}$ \\
\hline 11 & $\begin{array}{l}4.00 \\
4.47\end{array}$ & $\begin{array}{l}0.344 * \\
*\end{array}$ & 22 & $\begin{array}{l}4.36 \\
4.39\end{array}$ & $\begin{array}{l}0.481 * \\
*\end{array}$ & 33 & $\begin{array}{l}4.08 \\
4.64\end{array}$ & $\begin{array}{l}0.335 * \\
*\end{array}$ & 44 & $\begin{array}{l}3.31 \\
3.85\end{array}$ & $\begin{array}{l}0.420 * \\
*\end{array}$ \\
\hline
\end{tabular}




$$
\begin{array}{r}
\text { Notes: }{ }^{*}=\text { As noted before, the description of items is available at } \\
\text { http://www. outofservice.com/bigfive/; }
\end{array}
$$

Table 7 shows that all correlations were significant at the 0.01 level. They were divided into two groups according to the size of the effect based on the suggestions given for the interpretation of effect size by Tenjović and Smederevac [24]. A correlation of $r=0.364$ or higher indicated a strong effect, and lower correlations were interpreted as an effect of medium intensity. Strong effects were indicated for 25 of the questionnaire items (having a coefficient of determination higher than 0.13), while the remaining 19 items had an effect of medium intensity (with a coefficient of determination greater than 0.05).

When interpreting the results, it should be noted that items $2,6,8,9,12,18,21$, $23,24,27,29,31,34,35,37$ and 43 were recoded such that the lower arithmetic mean indicated a greater severity of the dimension. Taking this into account, it is apparent that the best predictor of the evaluation of a good teacher is item 29: I see myself as a person who is mostly in a good mood $(\mathrm{r}=0.832)$. There was also a strong effect for another 24 items. In fact, for more than half of the items there was a relatively pronounced effect of self-assessment on the evaluation of a good teacher.

If we take the effect size as a criterion, among the 25 items with a strong effect, eight related to openness to experience, seven to agreeableness, five to neuroticism, three to extraversion and two to conscientiousness. This means that at the level of individual items, a good teacher was evaluated primarily on the basis of statements relating to aspects of openness to experience and agreeableness. The exception to this is (good) mood which is classified within the domain of neuroticism, but it is certainly related to pleasant (agreeable) and open (nonconventional) behaviour. It seems that the good mood of a teacher was the most important characteristic on which evaluations of a "good teacher" were made.

Among the remaining 19 items with medium influence, seven related to conscientiousness, five to extraversion, three to neuroticism, three to openness to experience and one to agreeableness. This again confirms that descriptions of behaviour related to conscientiousness and extraversion played a smaller role in evaluations of a good teacher. In addition, the results are in line with the findings of the previous statistical analyses, wherein openness, agreeableness and neuroticism were better predictors of evaluations of a good teacher than extraversion and conscientiousness. Student evaluations of a teacher were primarily formed based on the degree to which the teachers were open to experience, agreeable and emotionally stable.

If these results are viewed in relation to teachers' responsibilities in contemporary schools, which need more student-centred situations, and teachers who know their students' learning characteristics [25], it seems that the expectations of students toward personality traits of a good teacher and the responsibilities are in line: it is 
expected from a good teacher to have the obtained personality structure to incite the students self-actualization.

\subsection{Validation of the Third Hypothesis: Differences in the Prediction of Good Teacher Evaluations Based on Personality Characteristics of Students from Different Faculties}

We assumed that there would be no differences between the groups of students from different faculties, and that self-assessments of personality would explain the same percentage of the common variance in the evaluation of a good teacher within both groups of students. To test this hypothesis we compared the predictive power of self-assessments at the domain level for the two subsamples by determining the bivariate correlation between BFI self-assessments and evaluations of a good teacher. In addition, we compared the group results using standard regression analysis. The results are shown in Tables 8 and 9.

Table 8

Correlations between self-assessments and evaluations of a good teacher on BFI dimensions for students of natural and technical sciences (subsample A) and social and humanistic sciences (subsample B) (Pearson's r)

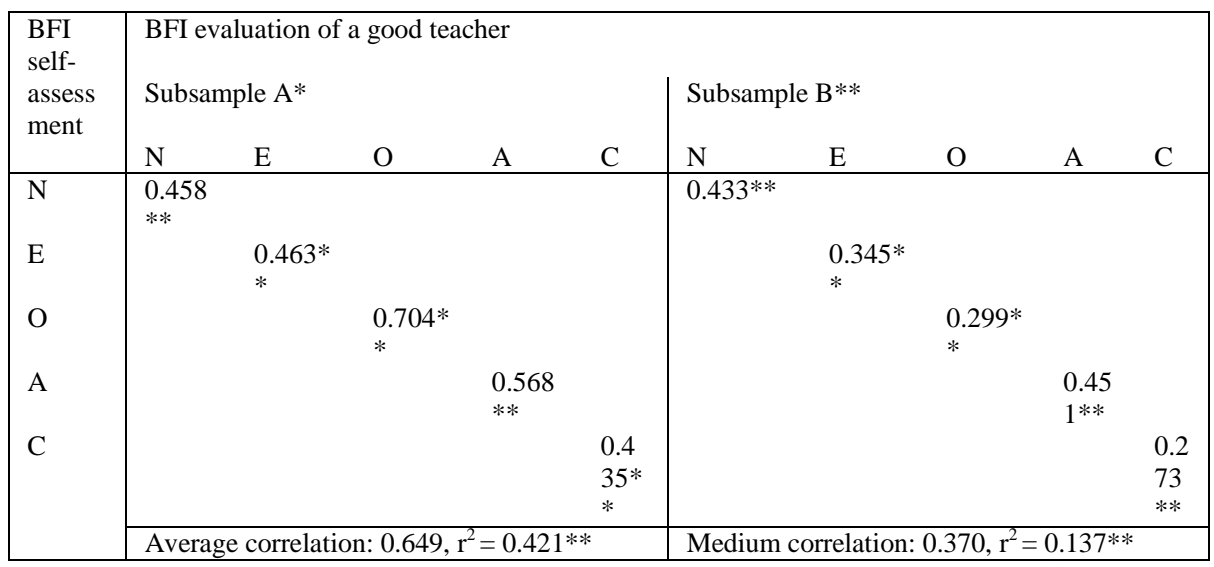

Notes: $N=$ neuroticism; $E=$ extraversion; $O=$ openness to experience; $A=$ agreeableness; $C=$ conscientiousness. $* p<0.05 ; * * p<0.01$. * indicates students of computer sciences; $* *$ indicates students of humanities

Comparisons of correlations for the two subsamples (Table 8) show some significant differences. In subsample A the correlation between all selfassessments and evaluations of a good teacher $(\mathrm{r}=0.649)$ was significantly higher than in subsample $B(r=0.370)$. The difference of $r=0.279$ was highly significant ( $p<0.0001)$.The medium correlation for subsample A explains more than $42 \%$ of the common variance of the evaluation, whereas in subgroup B the selfassessments explain less than $14 \%$ of the common variance. This means that 
personality traits are far better predictors of perceptions of a good teacher for the students of natural and technical sciences compared with students of social and humanistic sciences. In addition, for the students of natural and technical sciences, all dimensions contributed to the common variance of the evaluation of a good teacher above 18\%; the effects of openness to experience $(49.56 \%)$ and agreeableness $(32.26 \%)$ were particularly pronounced. For the students of social and humanistic sciences, only agreeableness and neuroticism explained about $20 \%$ of the common variance of the evaluation of teachers. In addition, the order of the impact of individual dimensions for the two subsamples was different.

Table 9

Standard multiple regression analysis for the students of natural and technical sciences (subsample A) and social and humanistic sciences (subsample B): evaluation of the model in terms of the prediction of BFI dimensions of a good teacher and the partial contributions of predictors

\begin{tabular}{|c|c|c|c|c|c|c|}
\hline M & $\mathrm{r}$ & $r^{2}$ & $\begin{array}{l}\text { Corrected } \\
\mathrm{r}^{2}\end{array}$ & $\begin{array}{l}\text { Standard } \\
\text { error } \\
\text { of estimate }\end{array}$ & $\mathrm{F}$ & $\mathrm{p}$ \\
\hline 1 & 0.688 & 0.473 & 0.456 & 10.634 & 28.029 & 0.000 \\
\hline 1 & 0.456 & 0.208 & 0.198 & 11.962 & 21.118 & 0.0001 \\
\hline \multirow[t]{6}{*}{1} & \multicolumn{3}{|c|}{ Subsample A predictors } & Beta & $\mathrm{t}$ & $\mathrm{p}$ \\
\hline & $\mathrm{N}$ & & & 0.219 & 3.488 & 0.001 \\
\hline & $\mathrm{E}$ & & & 0.095 & 1.483 & 0.140 \\
\hline & $\mathrm{O}$ & & & 0.516 & 8.149 & 0.000 \\
\hline & A & & & 0.222 & 3.363 & 0.001 \\
\hline & $\mathrm{C}$ & & & 0.102 & 2.055 & 0.001 \\
\hline \multirow[t]{6}{*}{1} & \multicolumn{6}{|c|}{ Subsample B predictors } \\
\hline & $\mathrm{N}$ & & & 0.146 & 2.203 & 0.029 \\
\hline & $\mathrm{E}$ & & & 0.223 & 3.319 & 0.001 \\
\hline & $\mathrm{O}$ & & & 0.146 & 2.297 & 0.023 \\
\hline & A & & & 0.209 & 3.015 & 0.003 \\
\hline & $\mathrm{C}$ & & & 0.050 & 0.713 & 0.447 \\
\hline
\end{tabular}

Notes: $M=$ model. Predictors: self-assessment of neuroticism $(N)$, extraversion $(E)$, openness $(O)$, agreeableness $(A)$ and conscientiousness $(C)$. Dependent variable: BFI - good teacher

Within the regression model, the evaluation of a good teacher was the criterion, and raw scores for the BFI dimensions were the predictors. The model for the whole of subsample A was statistically significant $\left(\mathrm{F}_{(5,156)}=28.029, \mathrm{p}<0.001\right)$ and explained $47.3 \%$ of the criteria. Similar results were obtained for the bivariate correlation. The regression model shows that each predictor, with the exception of neutoticism, significantly contributed to the prediction (openness to experience had the greatest partial contribution), but the intensity of the relationship was weaker than the linear correlation has shown. In subsample B the model was also statistically significant $\left(\mathrm{F}_{(5,226)}=7.939, \mathrm{p}<0.001\right)$ and explained about $15 \%$ of the common variance of the evaluation. Each predictor, except conscientiousness, contributed significantly to explaining the criterion (but only up to $4.97 \%$ for extraversion). If we compare the prediction effectiveness in the two subsamples, the difference is obvious. $\mathrm{F}$ values differ for 20.09 , which is highly significant ( $\mathrm{p}$ 
$<0.001$ ), and individual predictors explained a greater percentage of the criteria in subsample A compared with subsample B. This means that predictions based on the self-assessment of BFI dimensions were more successful for students of natural and technical sciences than students of social and humanistic sciences.

The results of both statistical tests were at odds with hypothesis three and suggested that the personality characteristics of the students of natural and technical sciences were better determinants of good teacher evaluations than those of social and humanistic sciences students.

\section{General Discussion}

The evaluation of teacher personality as the most important factor in educational work is the subject of many studies. This paper presents the results of a study in which students of natural and technical sciences and social and humanistic sciences were asked to evaluate the characteristics of a good teacher, based on the features included in the five-factor model of personality. We sought to answer two questions: (1) is it possible to predict the dimensions and personality traits attributed to a good teacher on the basis of personality characteristics of the appraisers; and (2) in which group of students is such prediction more successful?

The results for the sample as a whole suggested that the personality traits of the student assessors were significant predictors of their evaluations of a good teacher. All statistical analyses showed that a high percentage of the criterion variance (evaluations of a good teacher at the level of BFI dimensions or individual questionnaire items) could be explained on the basis of predictors (students' selfassessments for BFI dimensions or items of the questionnaire). The percentage for dimensions as predictors based on either the total sample or the student groups (determined by linear correlation and regression analysis) was about $20 \%$ (with the canonical correlation it was $28.5 \%$ ). In both cases the intensity of the different dimension contributions in explaining the criteria followed the same order. The most significant contribution was from openness to experience, followed by (in descending order): agreeableness, neuroticism, extroversion and conscientiousness. The students' evaluation of the teacher was primarily formed based on perceptions of the teacher's openness to experience, agreeableness and emotional stability. The intensity of the domain influence ranged from strong $(24.5 \%)$ to medium $(9.8 \%)$ when determined by linear correlation. However, when the impact of overlapping between the predictor variables (which is the result of interactions between domains and the disruptive effects of the sample characteristics) was removed, the predictive power of the domains was significantly reduced. Only openness to experience remained a significant predictor. Analysis at the level of individual questionnaire items revealed the percentage of common variance to be $15 \%$, which is a finding worth mentioning. 
In addition, the self-assessments of the natural and technical sciences students contributed significantly more to the aforementioned regularities than those of students in social and humanistic disciplines. The percentage of explained variance of criteria based on dimensions was $42 \%$, with each dimension making a significant contribution. The self-assessments of social and humanistic sciences students were not at odds with these findings, but their impact was less pronounced and less convincing.

The current study found that the evaluations of a good teacher were largely determined by properties of the assessor. When applied to educational practice, this essentially means that such evaluations may vary depending on the personality characteristics of pupils or students with whom the teacher works. This inevitably raises the question of what the desired personality of the staff in the pedagogical profession should be. This question is often approached in a somewhat naive form: is there a personality profile that would be ideal for educational work? If we define the ideal teacher as a teacher who is, according to their personality characteristics, optimally suitable to all students or groups of students with whom some form of pedagogical intervention is required, the answer is negative. Attempts to determine such a personality profile are doomed to failure because the goal is too general, and thus unrealizable. The reason is simple: the needs of members of all those groups with whom teachers work, especially in grammar schools, vary as much as general human needs. A desirable structure of personality in educational work can be determined only in relation to the structure of personality of pupils/students. Greater heterogeneity of educational groups reduces the likelihood that the educator's personality would optimally suit all in such a group. It seems that the essential psychological characteristics of teachers likely to be perceived as good, at least with respect to the properties covered by the BFI questionnaire, are properties of the openness to experience dimension, and also include the aspects of agreeableness and neuroticism that are necessary for good interpersonal relationships. Moderate extraversion and conscientiousness are additional characteristics of a good teacher.

\section{Conclusions}

This paper investigates to what extent students' personality traits can predict their attribution of the personality characteristics which a good teacher should have, and whether this prediction is more successful with students of natural and technical sciences, or with students of social sciences and humanities. A significant positive correlation between self-assessed personality traits and assessed traits of a good teacher was predicted. It was also assumed that in both groups the variance in ratings of a good teacher would be explained by personality traits of students to the same extent.

The analysis of the results revealed the following regularities:

1) Evaluations of personality qualities of a good teacher are determined by the personality characteristics of the assessors. Various correlational analyses of the 
relationship between self-assessment and the evaluation of a good teacher for the BFI domains for the entire sample indicated about $20 \%$ of the common variance, i.e. a strong effect of the predictors on the criterion.

2) Self-assessments for the dimensions of openness to experience, agreeableness and neuroticism were better predictors of a good teacher than self-assessments in the domain of extraversion and conscientiousness. Students with a high degree of openness to experience and agreeableness, and low neuroticism (i.e. expressed emotional stability) required these domains to be even more pronounced in a good teacher, and conservative assessors preferred even greater conservatism from teachers.

3) Standard regression analysis showed that the dimension of openness had the highest predictive power, followed by (in descending order): agreeableness, neuroticism, extroversion and conscientiousness. However, when the potential impact of disruptive variables was removed, only openness to experience maintained an effect of medium intensity in estimating the variance of a good teacher.

4) Analysis at the level of individual items revealed that $15 \%$ of the variability in the assessment of a good teacher could be explained by the self-assessment. The evaluation of a good teacher was primarily based on items from the domains of openness to experience and agreeableness, and on the grounds of items relating to (good) mood (the latter of which comes under the domain of neuroticism but relates to pleasant (agreeable) and open (unconventional) behaviour). It seems that the general mood of a teacher was the most important characteristic in evaluation of "a good teacher".

5) The personality characteristics of natural and technical sciences students were more successful predictors of evaluations of a good teacher than those of students in social and humanistic sciences.

The results have confirmed the first hypothesis. However, they are at odds with the second hypothesis.

\section{Acknowledgement}

The paper was written within the projects No 179010 and No 47020, supported by the Ministry of Education and Science of the Republic of Serbia. The authors are grateful to Louise Venables for her valuable comments and editing.

\section{References}

[1] K. Feldman: The Perceived Instructional Effectiveness of College Teachers as Related to Their Personality and Attitudinal Characteristics: A Review and Synthesis, Research in Higher Education, 24, 2, 1986, pp. 139-213

[2] S. Suplicz: What Makes a Teacher Bad? Trait and Learnt Factors of Teachers' Competencies, Acta Polytechnica Hungarica, 6, 3, 2009, pp. 125138 
[3] T. A. Lamke: Personality and Teaching Success. The Journal of Experimental Education, 20, 2, 1951, pp. 217-259

[4] R. B. Cattell, M. B. Marshall, S. Georgiades: Personality and Motivation: Structure and Measurement, Journal of Personality Disorders, 19, 1, 1957, pp. 53-67

[5] M. K. Mount, M. R. Barrick, G. L. Stewart: Five-Factor Model of Personality and Performance in Jobs Involving Interpersonal Interactions, Human Performance, 11, 1998, pp. 145-165

[6] A. Aidla, M. Vida: Personality Traits Attributed to Estonian School Teachers, Review of International Comparative Management, 11, 4, 2010, pp. 591-602

[7] J. M. Digman: Personality Structure: Emergence of the Five-Factor Model. Annual Review of Psychology, 41, 1990, pp. 417-440

[8] J. P. Rushton, J. Morgan, M. Richard: Teacher's Myers-Briggs Personality Profiles: Identifying Effective Teacher Personality Traits, Teaching and Teacher Education, 23, 4, 2007, pp. 432-441

[9] C. G. Jung: Psychological Types. Collected Works of C.G. Jung, Volume 6, Princeton University Press, Princeton, New Jersey, 1971

[10] G. J. Boyle: Myers-Briggs Type Indicator (MBTI): Some Psychometric Limitations, Australian Psychologist, 30, 1995, pp. 71-74

[11] H. Q. Li, Z. Y. Wu: Comparative Study on the Personality Patterns of "Good Teacher" and "Bad Teacher" as Perceived by College Students, Advanced Materials Research, 271-273, 2011, pp. 760-763

[12] H. J. Eysenck: Dimensions of Personality: 16, 5 or 3? - CRITERIA for a Taxonomic Paradigm, Personality and Individual Differences, 12, 8, 1991, pp. $773-790$

[13] C.-S. Liao, C.-W. Lee: An Empirical Study of Employee Job Involvement and Personality Traits: The case of Taiwan, International Journal of Economics and Management, 3, 1, 2009, pp. 22-36

[14] M. R. Barrick, M. K. Mount: The Big Five Personality Dimensions and Job Performance: A Meta-Analysis, Personnel Psychology, 44, 1, 1991, pp. 126

[15] T. A. Judge, D. Heller, M. K. Mount: Five-Factor Model of Personality and Job Satisfaction: A Meta-Analysis, Journal of Applied Psychology, 87, 3, 2002, pp. 530-541

[16] M. M. Sanchez, R. Martinez-Pecino, Y. T. Rodriguez, P. T. Menero: Student Perspectives on the University Professor Role, Social Behavior and Personality: An International Journal, 39, 4, 2011, pp. 491-496 
[17] L. Genc, J. Pekić, A. Genc: Struktura ličnosti dobrog nastavnika u modelu Velikih pet (Personality Structure of a Good Teacher from Students Perspective according to Big-Five Model), [Manuscript submitted for publication]

[18] S. A. Basow: Student Evaluations of College Professors: When Gender Matters, Journal of Educational Psychology, 87, 4, 1995, pp. 656-665

[19] O. P. John, S. Srivastava: The Big-Five Trait Taxonomy: History, Mesurement, and Theoretical Perspectives. In L. A. Pervin, O. P. John (eds.): Handbook of personality: Theory and research, Guilford Press, New York, 1999, pp. 102-139

[20] P. Čolović: Tipološka prespektiva u psihologiji ličnosti: tradicionalni i taksometrijski pristup (Typological Perspective in Personality Psychology: Traditional and Taxometric Approaches), Unpublished doctoral dissertation, Novi Sad, University of Novi Sad, Faculty of Philosophy, 2012

[21] S. Rózsa: A BFQ Tesztkönyve. Oktatási segédanyag, Budapest, ELTE Személyiség- és Egészségpszichológiai Tanszék (The BFQ Testbook: Educational Supplement, Budapest, ELTE, Personality and Health Psychology Department), 2000

[22] O. P. John, E. M. Donahue, R. L. Kentle: The Big Five Inventory: Versions 4a and 54, Institute of Personality and Social Research, University of California, Berkley, 1991

[23] J. Cohen: Statistical Power Analyses for the Behavioral Sciences ( $2^{\text {nd }}$ ed.), Erlbaum, Hillside, New Jersey, 1988

[24] L. Tenjović, S. Smederevac: Mala reforma u statističkoj analizi podataka: malo p nije dovoljno, potrebna je i veličina efekta (A Small Reform in the Data Analisys in Psychology: a Amll p is not Eough, Effect Size is Needed too), Primenjena psihologija, 4, 2011, pp. 317-333

[25] P. Tóth: Learning Strategies and Styles in Vocational Education, Acta Polytechnica Hungarica, 9, 3, 2012, pp. 195-216 